\title{
Income-based Inequality in Post-disaster Migration is Lower in High Resilience Areas: Evidence from U.S. Internal Migration*
}

\author{
Ted Hsuan Yun Chen ${ }^{1,2} \quad$ Boyoon Lee ${ }^{3}$
}

September 22, 2021

\begin{abstract}
Residential relocation following extreme weather events is among the costliest individual-level measures of climate change adaptation. Consequently, they are fraught with inequalities, with disadvantaged groups most adversely impacted. As climate change continues to exacerbate extreme weather events, it is imperative that we better understand how existing socioeconomic inequalities affect climate migration and how they may be offset. In this study we use network regression models to look at how internal migration patterns in the United States vary by disaster-related property damage, household income, and local-level disaster resilience. Our results show that post-disaster migration patterns vary considerably by the income level of sending and receiving counties, which suggests that income-based inequality impacts both access to relocation for individuals and the ability to rebuild for disaster-afflicted areas. We further find evidence that these inequalities are attenuated in areas with higher disaster resilience. However, because existing resilience incentivizes in situ incremental adaptation which can be a long term drain on individual wellbeing and climate adaptation resources, they should be balanced with policies that encourage relocation where appropriate.
\end{abstract}

Keywords: climate change adaptation; climate migration; inequality; disaster resilience; network analysis

\footnotetext{
${ }^{*}$ Corresponding author: Ted Hsuan Yun Chen (ted.hsuanyun.chen@gmail.com). We thank Lukas Fesenfeld, Isabelle Stadelmann-Steffen, Omer Yalcin, and conference participants at PolNet 2021, ECPR 2021, and ISA 2021 for their helpful feedback. We thank Xi Liu, Clio Andris, and Bruce Desmarais (2019) for sharing their replication materials. Data used in this study will be made publicly available on Zenodo upon publication of this paper, with the exception of SHELDUS variables, which were licensed for use by the Center for Emergency Management and Homeland Security, Arizona State University. Other replication materials will be made publicly available on GitHub.

${ }^{1}$ Faculty of Social Sciences, University of Helsinki

${ }^{2}$ Department of Computer Science, Aalto University

${ }^{3}$ Department of Political Science, Pennsylvania State University
} 


\section{Contents}

1 Introduction $\quad 1$

2 Methods $\quad 4$

2.1 Data and Measures . . . . . . . . . . . . . . . . . . . 4

2.1.1 Migration Flows . . . . . . . . . . . . . . . . . 5

2.1.2 Property Damage from Extreme Weather Events . . . . . . . . . . 5

2.1 .3 Income . . . . . . . . . . . . . . . . . . . . 6

2.1.4 Community and Institutional Resilience . . . . . . . . . . . . . . 7

2.2 Estimation and Testing . . . . . . . . . . . . . . . . 8

3 Results and Discussion $\quad 9$

3.1 Income-based Inequality in Post-Disaster Migration . . . . . . . . . . . . . . 9

3.2 Disaster Resilience is Associated with Lower Income-based Inequality . . . . 11

3.3 Climate Factors Associated with Inmigration . . . . . . . . . . . . . . . 13

4 Conclusion $\quad 14$

5 References $\quad 16$

$\begin{array}{ll}\text { A Confounding Variables } & 20\end{array}$

B Descriptive Statistics $\quad 21$

B.1 Community Capital and Institutional Capacity . . . . . . . . . . . . . . 21

B.2 Property Damage, Household Income, and Disaster Resilience . . . . . . . . 22

C Quadratic Assignment Procedure $\quad 23$

D Model Results $\quad 23$ 


\section{Introduction}

Climate change-induced extreme weather events are increasing in frequency and severity. From the California wildfires to hurricanes and floods along the United States' eastern seaboard and the Gulf Coast, damages and bodily harm caused by natural disasters and other extreme weather events are rising to record levels. Climate models predict these trends will continue (e.g. Wing et al. 2018; Kossin 2018; Trenberth, Fasullo and Shepherd 2015). Coastal flooding and sea-level rise alone could lead to massive amounts of displacement and destroyed property (Hauer, Evans and Mishra 2016). In addition to the overwhelming financial costs, exposure to natural disasters severely impact human welfare (Mills, Edmondson and Park 2007; Shultz and Galea 2017).

In the face of worsening climate change, transformational adaptations such as the relocation of vulnerable systems rather than incremental improvements are increasingly necessary (Kates, Travis and Wilbanks 2012). While these adaptations usually require overcoming difficulties associated with collective action, some have the benefit of being individually autonomous, meaning that their effectiveness to individuals does not hinge on coordinated behavior (Leary 1999). One such measure is residential relocation, whereby individuals or households move to different locations either to preempt or in response to the impacts of climate change (Adams and Adger 2013). Because there is considerable geographical consistency in climate patterns, those faced with the threat of climate change, such as natural disasters or other extreme weather events, can in principle choose to relocate their residences out of concern for their personal and economic welfare. Prior work shows, for example, that internal migration patterns in the U.S. vary by climate-related crop yields (Feng, Oppenheimer and Schlenker 2012) and exposure to natural disasters (Boustan et al. 2020; Eyer et al. 2018).

Despite the ostensible appeal of migration as a response to high concentrations of people living in increasingly inhospitable areas (Hauer, Evans and Mishra 2016) and to the fact that post-disaster reconstruction is often inefficient (Moore 2017) and can be taxing on individual wellbeing (Koslov et al. 2021), there are questions about the conditions under which migration is a viable adaptation measure to climate change, and how policies can be designed to facilitate these conditions.

First, because it relies primarily on individual-level means, climate migration is subject to existing socioeconomic inequalities (Warner and Afifi 2014). Most broadly applicable is the fact that, as one of the costliest individual-level climate adaptation measures, migration is an option limited to those with financial slack (McLeman and Hunter 2010). Natural disasters exacerbate these constraints as they can greatly devalue property. Government 
buyout programs are often not enough to offset relocation costs (Kick et al. 2011) and in many parts of the U.S., home insurance policies are set up in a way that the payout for relocation is lower than the payout for rebuilding (Insurance Information Institute 2021; United Policyholders 2021). Consequently, following natural disasters, poorer individuals often become trapped in afflicted areas because they lack the resources to relocate (Boustan et al. 2020; Angelucci 2015; Black et al. 2013).

Given the expectation that inequalities in climate migration are exacerbated by exposure to natural disasters, we ask whether they can be attenuated through disaster resilience measures, broadly defined as formal and informal institutions that improve an area's ability to withstand and rebound from natural disasters (Federal Emergency Management Agency 2021). Disaster resilience has a dualistic relationship with climate migration (Binder, Baker and Barile 2015). By definition, measures that improve resilience reduce the impact of disasters and speed up recovery, which should on the one hand lower barriers to relocation for individuals who want to do so. At the same time, they also reduce the incentives for relocating because in terms of adapting to climate change, relocation and resilience-building can be considered as short- to medium-term substitute for each other. Given existing investments in resilience, in situ incremental adaptations become more attractive (Binder, Baker and Barile 2015). Further, there is evidence that strong social capital, often understood as a form of resilience, can lower individuals' risk perceptions (Wolf et al. 2010) or even lead to post-disaster mooring effects (Aldrich 2012).

With these considerations in mind, we examine how internal migration patterns in the U.S. vary by disaster-related property damages and household income. We analyze these patterns at the county-dyad level over a ten year period from 2009 to 2018 using migration flow data. Because we view relocation as a measure of climate change adaption, we pay additional attention to questions about how to maintain fairness, specifically whether expected inequalities in climate migration can be offset by various disaster resilience measures.

As an initial exploratory data analysis that helps illustrate our research questions, we show in Figure 1 how the relationship among these three variables play out in U.S. counties afflicted by Hurricane Harvey. First, it is clear that there is income-based inequality in post-Harvey relocation, with richer counties overwhelmingly experiencing outmigration after Harvey, which fits well with our understanding that relocation is costly. Second, there is evidence of a resilience effect among poorer counties, which holds across two different measures of resilience, community capital and institutional capability. In the lowest resilience quartile, most poor counties saw decreased outmigration after Hurricane Harvey, and as resilience increases, the difference in outmigration patterns between richer and poorer counties becomes less apparent. 

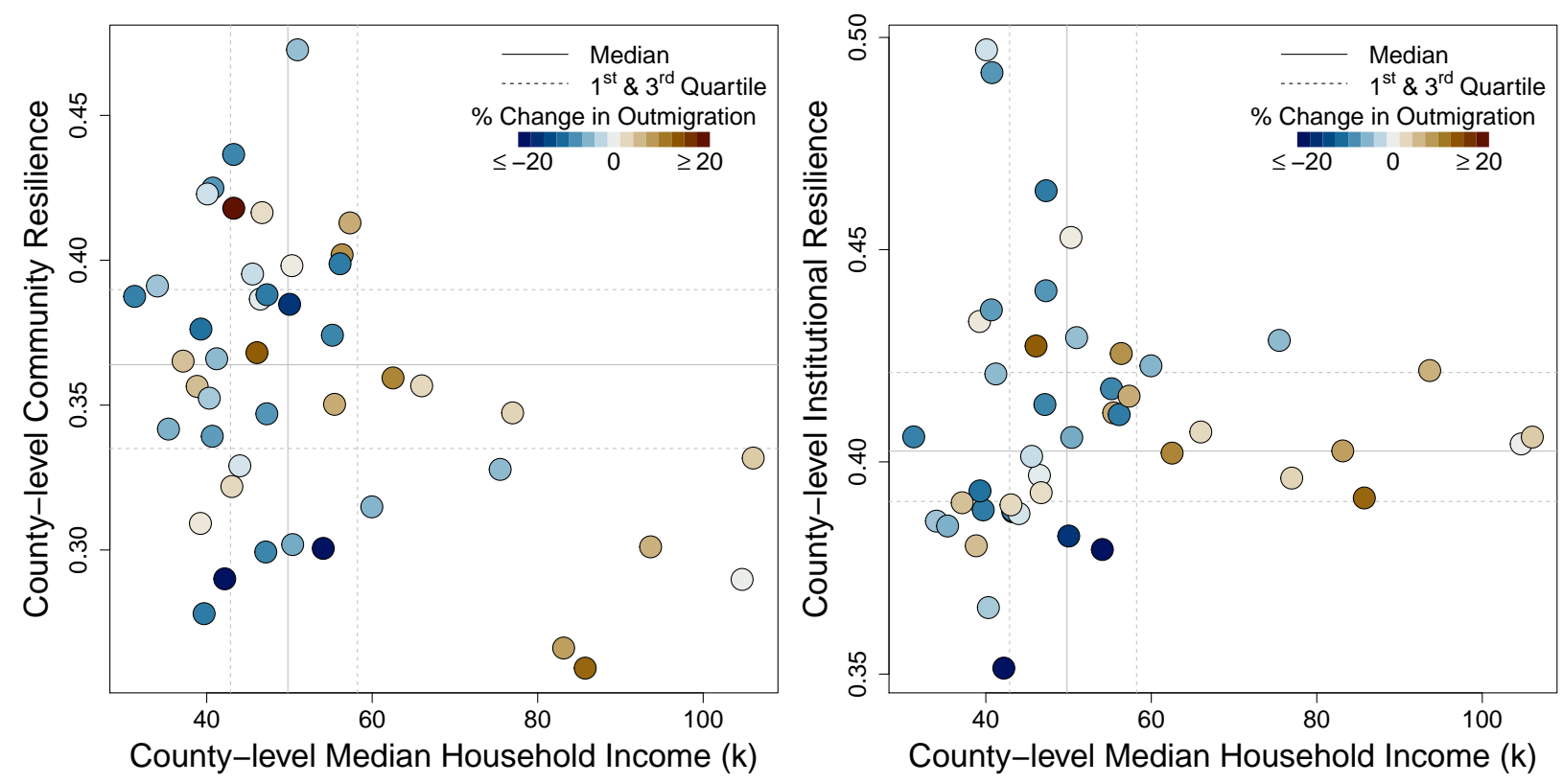

Figure 1: Post-disaster outmigration patterns after Hurricane Harvey in affected counties, by median household income and disaster resilience. Each point represents one of 45 Texas counties with population over 20,000 that were included in the Harvey disaster declaration. Point colors indicate percent change in outmigration in 2017, relative to average outmigration in the previous five years. These counties are placed on the $\mathrm{x}$-axis by county-level median household income, and on the y-axis by county-level resilience. The left-hand side figure shows community capital, which captures ties between local community members when it comes to preparing and responding to disasters, and the right-hand side figure shows institutional capacity, which captures the ability of local governments to coordinate and manage disaster-related resources.

In this exploratory data analysis, there is already evidence of patterns that speak to our research questions. In the remainder of this paper, we present findings from network regression models over a ten year period. We show that there is considerable heterogeneity in how households from different economic backgrounds respond to natural disasters using relocation. Those from richer neighborhoods leave disaster-damaged areas while poorer households lack the capacity to migrate away from worsening conditions despite being exposed to environmental risks. We then show evidence that these income-based inequalities in climate migration are attenuated in areas that have higher disaster resilience, both in terms of community capital and institutional capacity. Our findings speak to existing work that look at how individuals respond to the risk of climate change through decisions to relocate (Adams and Adger 2013; Piguet, Pécoud and De Guchteneire 2011), and those that examine how the impacts of natural disasters and individuals' ability to respond to them vary by existing socioeconomic inequalities (McCaughey et al. 2018; Black et al. 2013; Masozera, Bailey and Kerchner 2007).

A further benefit of our migration flow data is that it lets us study the entire migration calculus when individuals are faced with natural disasters, from when they leave to where 
they go, thereby providing additional insights into how people consider climate factors when choosing where to live. We find evidence that richer areas can still attract inmigration even after being afflicted by natural disasters while poorer areas do not. Additionally, the level of disaster resilience in an area does not appear to be an important consideration to attracting inmigration. Beyond engaging with prior evidence that suggest people do not or cannot account for the climate-related features of where they move to (Hino and Burke 2021; Bell et al. 2021), which reduces the efficacy of climate migration as a climate adaptation measure, our findings show that post-disaster relocation is a driver of societal restructuring with economic (Feng, Oppenheimer and Schlenker 2012; Boustan et al. 2020) and social (Molloy, Smith and Wozniak 2011; Hopkins 2012) implications.

\section{Methods}

To study how post-disaster relocation in the U.S. varies by income levels and disaster resilience, we compiled a network data set that comprises 1) the internal migration flow between counties in the U.S. and 2) county-level characteristics such as disaster exposure and median household income. Our data exist annually for the decade from 2009 to 2018. Using this data set, we fit annual gravity models of internal migration, which allows us to study how county-level characteristics relate to both outmigration and inmigration. Our main focus is on the interaction effects between exposure to natural disasters, household income, and local disaster resilience, which we show using hypothesis tests on the model coefficients and marginal effect plots.

\subsection{Data and Measures}

We combined meteorological, administrative, and academic sources to create our annual network data set from 2009 to 2018. For computational reasons, we excluded counties with population levels below 20,000 from our data set. Additionally, to account for any different migration behaviors due to long distances to the mainland, we also excluded all Alaskan and Hawaiian counties (and equivalent administrative units). These subsetting steps reduced the number of counties to 1,834, but retain over $90 \%$ of all internal migration in the U.S.

Table 1 provides an overview of our data set, including key variables, their source, and how they were included in our models. We outline detailed information on key variables below, and discuss confounding factors in Appendix A. 


\begin{tabular}{|c|c|c|c|c|}
\hline \multirow[b]{2}{*}{ County-level Measure } & \multirow[b]{2}{*}{ Source } & \multicolumn{3}{|c|}{ Included Model Terms } \\
\hline & & Sender & Receiver & Dyad* \\
\hline Disaster-induced Property Damage & SHELDUS & $\cdot$ & $\bullet$ & \\
\hline Median Household Income & ACS & - & • & - \\
\hline Community Capital Resilience & BRIC & • & - & \\
\hline Institutional Capability Resilience & BRIC & • & • & \\
\hline Population & ACS & • & • & - \\
\hline Median Age & ACS & • & • & • \\
\hline Percent Bachelors or higher & ACS & • & - & • \\
\hline Percent Unemployed & ACS & • & - & • \\
\hline Percent White Population & ACS & - & - & - \\
\hline Percent Native-born Population & ACS & - & - & \\
\hline GOP Vote Share & MIT Election Lab & • & • & • \\
\hline Percent Manufacturing Employee & NAICS & & • & \\
\hline Disaster-induced Bodily Harm & SHELDUS & - & - & \\
\hline Geographical Location & - & & & - \\
\hline State & - & & & - \\
\hline
\end{tabular}

*Dyadic measures are distance/similarity/homophily terms depending on the base measure.

Table 1: Summary of Variables and Model Terms.

\subsubsection{Migration Flows}

Our outcome variable is county-to-county annual migration flow. We obtained this data from the U.S. Internal Revenue Service (IRS), which estimates county-to-county migration using taxpayers' filing addresses. A taxpayer or taxpaying household is considered to have moved in a given year if their return address changed from the previous year's address. In other words, migration in year $t$ represents change in residence between years $t$ and $t+1$. This data source has been used in prior studies of U.S. internal migration (e.g. Eyer et al. 2018; Liu, Andris and Desmarais 2019). While the data set provides both the number of individuals and households that moved, we focus on households migration because climate events affect households as a whole rather than at the individual level. We log-transformed the migration flow before fitting our models to account for observed dyads with extremely high migration levels.

\subsubsection{Property Damage from Extreme Weather Events}

We use disaster-induced property damages to capture the severity and impact of natural disasters on individuals living in a county, as economic losses is a widely-observed outcome after natural disasters. We obtained damage estimates from the Spatial Hazard Event and Loss Database for the United States (SHELDUS; CEMHS 2020). This database, which is 

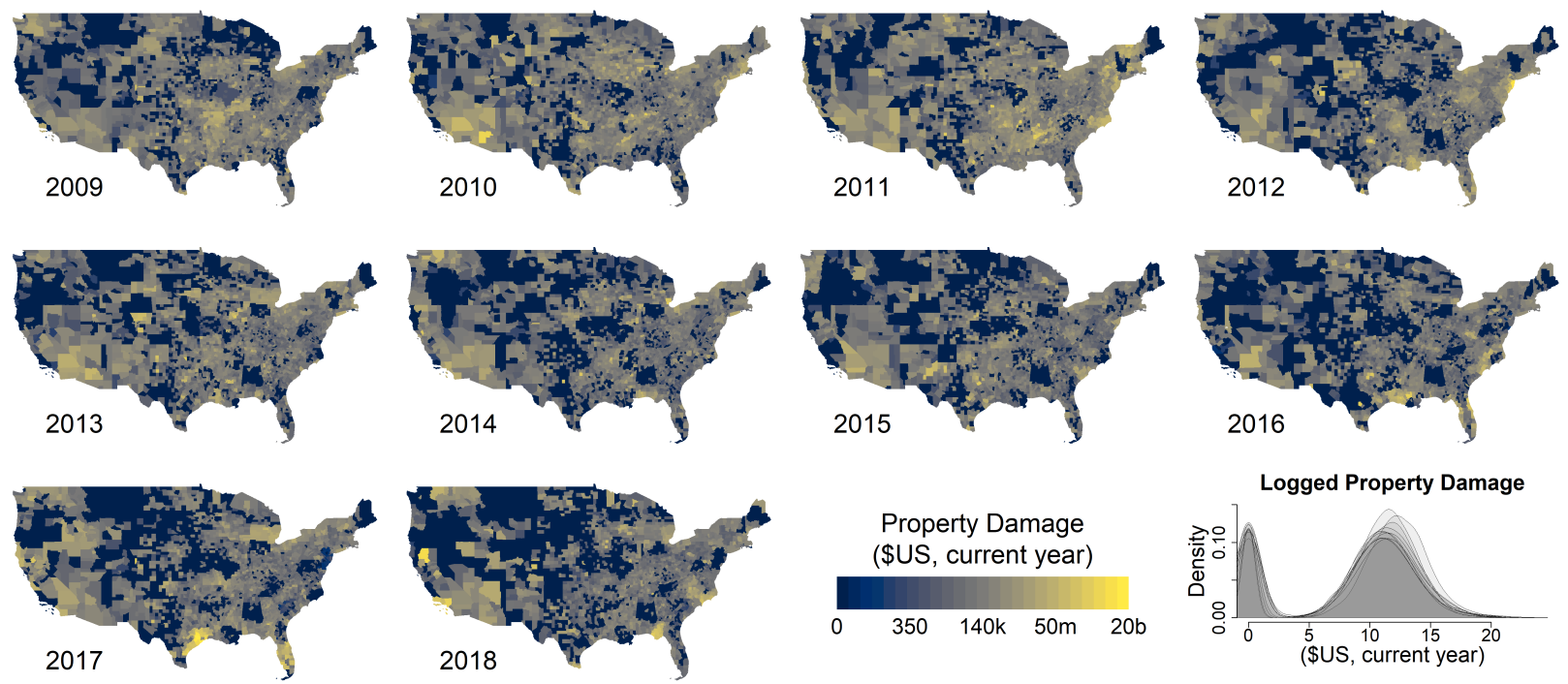

Figure 2: Geographical distribution of disaster-induced property damage. Lighter color indicates greater economic losses in U.S. dollars. Data obtained from Spatial Hazard Event and Loss Database for the United States.

widely used in disaster and hazard research (e.g. Borden and Cutter 2008; Cortés and Strahan 2017; Doktycz and Abkowitz 2019), was constructed based on data from the National Weather Service and contains estimates of economic losses and the number of bodily harms at the county level. Estimates of property damage, specifically, combines multiple sources including insurance companies, emergency managers, U.S. Geological Survey, U.S. Army Corps of Engineers, power utility companies, and newspaper articles (CEMHS 2020). SHELDUS records property damage in actual U.S. dollars, resulting in a right-skewed distribution. To account for this, we used the log-transformed property damage in our models.

Figure 2 shows the distribution of property damages across the U.S. While there are persistent patterns in the regions that experience the most damages - coastal areas prone to flooding and other hurricane damages, wildfire and drought areas in the west and southwest - there is considerable year-to-year variation that improves our model inferences.

\subsubsection{Income}

To measure economic capacity, we use county-level median household income from the American Community Survey (ACS) 5-year estimates, which includes income and benefits in U.S. dollars adjusted by inflation. Similar to property damage, we log-transformed our income data before including it in our models. 


\subsubsection{Community and Institutional Resilience}

We study two kinds of local disaster resilience, community capital and institutional capacity, which respectively represents the informal and formal sides of local-level measures that facilitate coping with disaster-related disruptions (Cutter, Ash and Emrich 2014). Among many factors contributing to local resilience, previous studies have emphasized the importance of these informal social capital and formal governance structures in particular (Tierney 2012). First, denser social networks and tighter bonds within the community are mechanisms that allow afflicted areas, even those with lower wealth, to overcome severe disaster-related damages (Aldrich 2012). Close social connections among community residents facilitate postdisaster recovery and reconstruction because they make the necessary coordination smoother (Cox and Perry 2011; Aldrich and Meyer 2015). Similarly, the capacity of formal institutions, obtained through preparedness training and disaster experience, affords effective collaboration among relevant actors in the face of disasters, which is required for quick response and mobilization of resources (Chen et al. 2013). In this sense, institutional capacity is crucial to disaster resilience because it is directly tied the ability of communities to reduce socioeconomic vulnerability (Papathoma-Köhle, Thaler and Fuchs 2021).

We capture these two types of local resilience using measures from the Baseline Resilience Indicators for Communities index (BRIC; Cutter, Ash and Emrich 2014; Cutter and Derakhshan 2020), which has been a standard data set in the disaster resilience literature and was recently adapted for the Federal Emergency Management Agency's National Resilience Index (Zuzak et al. 2020). Both resilience measures are index variables in the $[0,1]$ range with 1 meaning higher community resilience. The community capital measure, which captures the connectivity among local citizens and their ability to assist neighbors in emergency situations, is based on variables related to volunteerism, religious affiliation, attachment to place, political engagement, citizen disaster training, and civic organizations. The institutional capacity measure, which captures aspects related to local government coordination in managing and assigning resources during a disaster, is based on variables regarding mitigation spending, flood insurance coverage, governance performance regimes, jurisdictional fragmentation, disaster aid experience, local disaster training, population stability, nuclear accident planning, and crop insurance coverage.

Since the indices are only available for two time points, 2010 and 2015, we used the one that is more temporally-proximate to each given year in our data set. Specifically, the local resilience measures for 2010 are used for 2009-2012, and the 2015 measures are used for $2013-2018 .^{1}$

\footnotetext{
${ }^{1}$ In Appendix B, we present the marginal and joint distributions of these variables that show the two measures to be not strongly correlated with each other, but internally consistent across time.
} 


\subsection{Estimation and Testing}

We combined the data described above to fit annual network regression models where the outcomes are annual directed networks with logged migration flow edges and county- and dyad-level covariates as predictors. Our focus is on the predictors discussed above and their interactions, but this network framework allows us to control for the host of confounders summarized in Table 1. In these network models, coefficient estimates on predictors are obtained using ordinary least squares (OLS), while testing for statistical significance is based on permutation methods because using standard errors from OLS estimation with our interdependent county-dyad observations will lead to over-rejection of the null hypotheses (Dekker, Krackhardt and Snijders 2007).

Specifically, to account for interdependence between dyadic observations in our network data, we used the multiple regression quadratic assignment procedure (MRQAP) to construct null distributions based on all model terms except for the tested ones, which are used for hypothesis testing (Krackhardt 1988). We construct our MRQAP null distributions using residual-based permutation, which have been shown in simulation studies to perform better compared to other permutation approaches (Dekker, Krackhardt and Snijders 2007). ${ }^{2}$ Residual-based permutation methods have additionally been shown to work well for testing interaction effects (Buzkova 2016), which is the focus of our study.

Similar to prior work that use this network approach to studying migration patterns (e.g. Liu, Andris and Desmarais 2019; Schon and Johnson 2021), we fit separate annual models instead of coercing all coefficients to be the same. This immensely reduces computational requirements at little cost to inferential validity; as our results show, we have enough power to detect hypothesized effects, and the estimated coefficients are consistent across annual models.

We fit a set of three models for each year in our data set. The base model, for which dyad $i j$ has sending county $i$ and receiving county $j$, is

$$
\begin{aligned}
\text { Migration }_{i j} & =\beta_{1} \text { PropDamage }_{i}+\beta_{2} \text { HouseholdInc }_{i}+\beta_{3} \text { PropDamage }_{i} \times \text { HouseholdInc }_{i} \\
& +\beta_{4} \text { PropDamage }_{j}+\beta_{5} \text { HouseholdInc }_{j}+\beta_{6} \text { PropDamage }_{j} \times \text { HouseholdInc }_{j} \\
& +\beta_{7} \text { CommResil }_{i}+\beta_{8} \text { CommResil }_{j}+\beta_{9} \text { InstResil }_{i}+\beta_{10} \text { InstResil }_{j} \\
& +\boldsymbol{X}^{\prime}{ }_{i j} \boldsymbol{B}+\beta_{0}+\epsilon_{i j}
\end{aligned}
$$

\footnotetext{
${ }^{2}$ Depending on the test, we used either the double semi-partialling permutation method (Dekker, Krackhardt and Snijders 2007) or the Freedman-Lane semi-partialling permutation method (Freedman and Lane 1983). Details of the MRQAP approach and the different permutation methods used in this study are presented in Appendix C.
} 
From each of these base models, we examined the effect of ten predictors measuring disaster exposure, household income, resilience, and their interactions on in- and outmigration (i.e. $\left.\beta_{1}, \beta_{2}, \ldots, \beta_{10}\right)$. In two extensions to the base model, we allowed the interactive effect of property damage and household income on outmigration to vary by, respectively, community capital resilience and institutional capacity resilience in the sending county.

In addition to directly testing coefficients, we present the main focus of our study, the interactive effects of property damage and household income using marginal effect plots that show how the effect of exposure to natural disasters vary by county-level median household income. In a second set of results, we further disaggregated these marginal effects by countylevel disaster resilience. For clarity of presentation, we computed these effects as the percent change in migration flow when county-level property damage increases from none to the median observed value in the given year. Statistical significance of these marginal effects is also tested using the MRQAP.

\section{Results and Discussion}

Figure 3 reports the yearly coefficient estimates for our predictors of interest from our base model (i.e. Equation 1). While there are some variations across years, most of the reported terms have relatively stable estimates.

\subsection{Income-based Inequality in Post-Disaster Migration}

The positive coefficient estimates for the interaction term between median household income and disaster-induced property damage combined with the negative coefficients estimates on both base terms indicate that internal migration in the U.S. is responsive to natural disasters, but the response pattern differs by the economic status of those affected. Specifically, while individuals living in richer areas are generally less likely to move (i.e. negative coefficient estimate on the household income outmigration term) - which comports with findings from the broader migration literature (Clemens 2014; Molloy, Smith and Wozniak 2011) - they are more likely to respond to disaster-induced property damage by relocating from afflicted areas. Conversely, individuals from poorer areas tend to move more frequently, but become more immobile after being exposed to disaster-related property damages.

We illustrate the substantive effect of income in modifying the relationship between natural disasters and outmigration flows using the marginal effect plot on the left-hand side of Figure 4. Here, the curves present, by year, how the percent change in county-level outmigration given median observed values of disaster-induced property damage varies by 

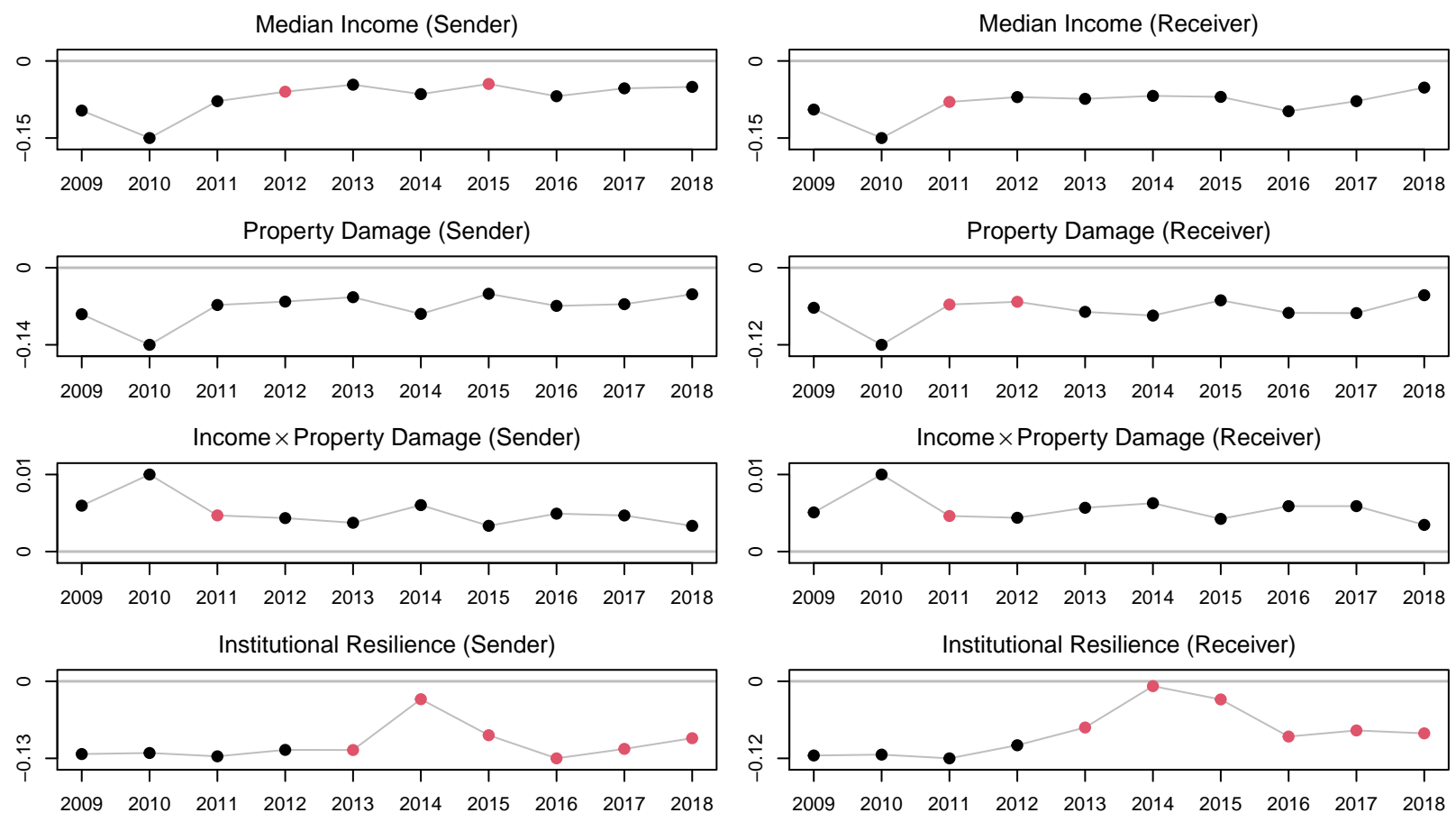

Community Resilience (Sender)
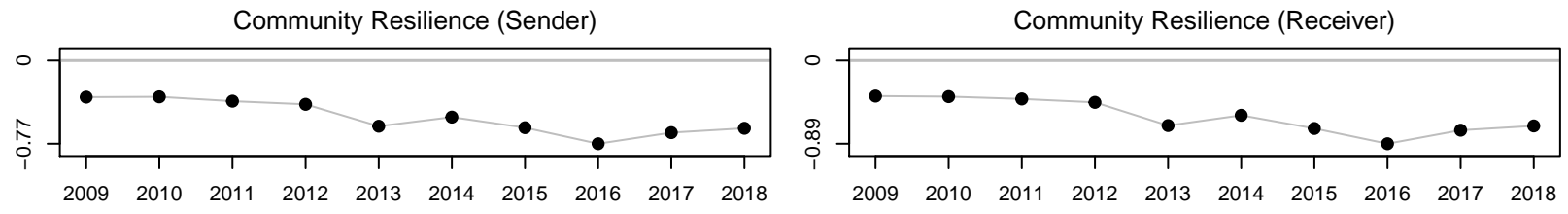

Figure 3: Coefficient plot for key predictors. Black dots indicate statistical significance at the 0.05 level tested using MRQAP null models.

county-level income. ${ }^{3}$ As the figure shows, property damage in poor counties is associated with a statistically significant decrease in outmigration of approximately $5 \%$. This pattern holds across all years, indicating that there is a robust effect of property damages in decreasing outmigration when those afflicted lack resources to cope with damages. As the afflicted area becomes richer, the pattern is reversed. At a sufficiently high level of median household income, exposure to disaster-related property damage is associated with approximately $5 \%$ increase in outmigration, which is statistically significant in five of the ten annual models.

In sum, the results here indicate that households in richer areas are more likely to relocate after experiencing natural disasters when compared to otherwise normal times, while households from poorer areas become less likely to do so following natural disasters. These findings offers evidence corroborating our prior discussion on the existence of income-based inequality in post-disaster migration. Given their lack of resources, poorer households are likely to become trapped in disaster-afflicted areas. The implication of this is that where

\footnotetext{
${ }^{3}$ Data coverage for the variables that constitute the interaction terms is presented in Appendix B.
} 

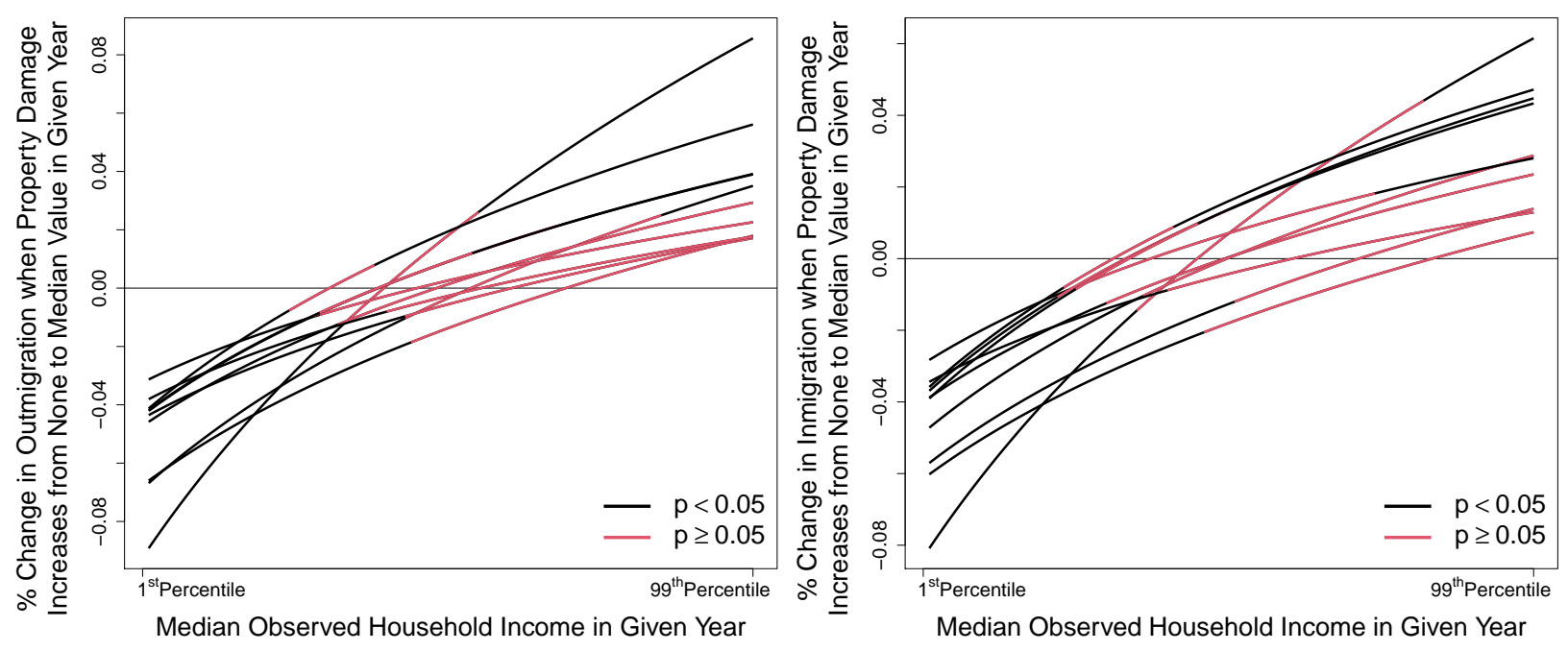

Figure 4: Marginal effect plots showing the existence of income-based inequality in climate migration. Plotted curves show percentage change in migration flow when counties experience property damage at the median observed value in a given year, varying by county-level median household income. The left-hand side figure shows outmigration patterns while the right-hand side figure shows inmigration patterns. Each curve represents one study year from 2009 to 2018.

there access to adaptation measures is unequal, climate change is likely to exacerbate existing socioeconomic inequalities.

\subsection{Disaster Resilience is Associated with Lower Income-based Inequality}

To see how local features that reduce the impact of disasters affect income-based inequality in post-disaster migration, we extended the base model by allowing the interaction effect between household income and property damage to further vary by two different types of disaster resilience. Our results, presented as marginal effects plots in Figure 5, indicate that both community capital and institutional capacity are statistically significant predictors of whether income-based inequality in post-disaster migration exists in a county. In these marginal effects plots, the curves again present how the effect of property damage on countylevel outmigration varies by county-level income. In both sides of the figure, there are two sets of curves, with the solid lines representing low resilience counties and the dotted lines representing high resilience counties.

As the solid lines in Figure 5 show, in counties with low disaster resilience, income-based inequality in post-disaster migration follows a similar pattern as in the base model which does not consider disaster resilience. In poorer counties, individuals are less likely to move out after exposure to natural disasters, whereas those from richer counties are instead more likely to leave. The strength of the relationship in both extended models is much stronger than in 

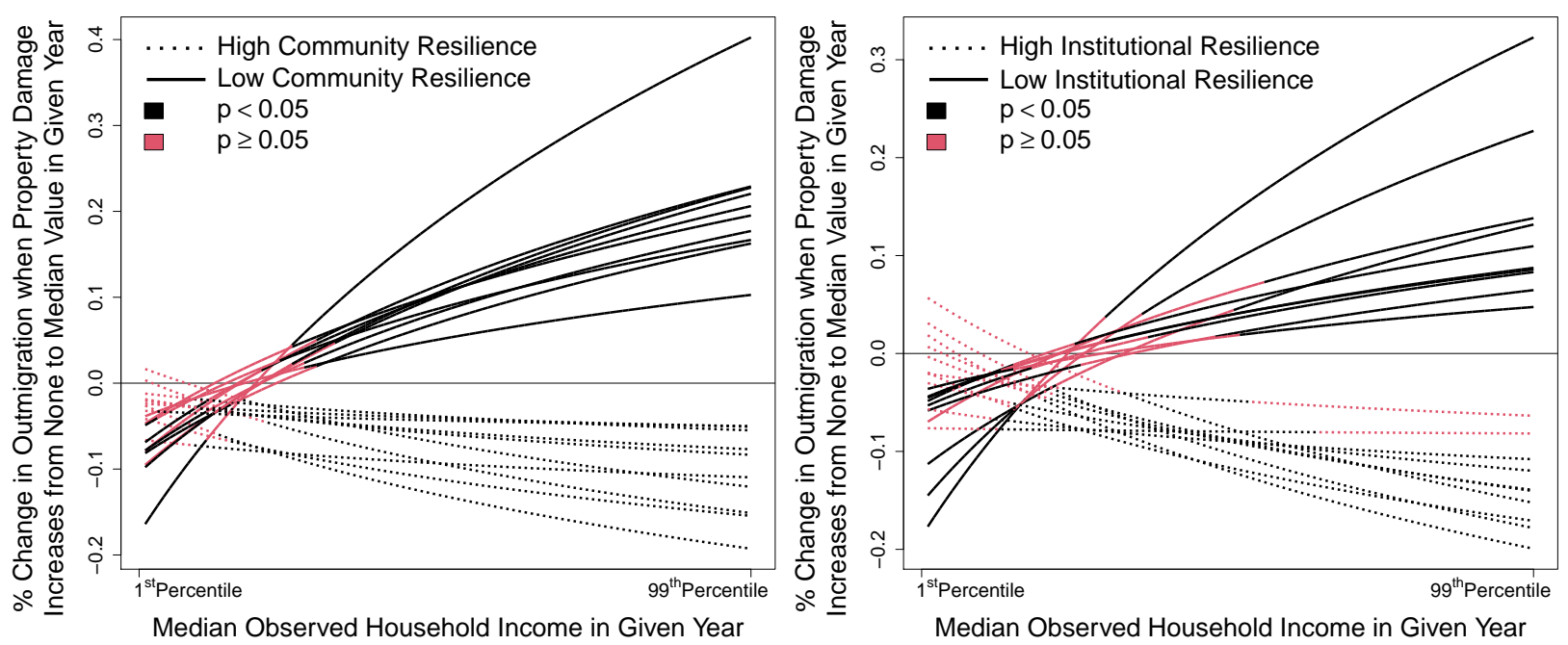

Figure 5: Marginal effect plots showing the attenuating effect of disaster resilience on income-based inequality in climate outmigration. Plotted curves show percentage change in migration flow when counties experience property damage at the median observed value in a given year, varying by county-level median household income, and by county-level resilience. The left-hand side figure shows variation based on community capital while the right-hand side figure shows variation based on institutional capacity. Each curve represents one study year from 2009 to 2018.

the base model, with the estimated percent change in most years ranging from - $10 \%$ to $20 \%$ when going from the lower end of the income range to the higher end, whereas the same figures in the base model is estimated to be a much smaller $-6 \%$ to $4 \%$ range. When looking at counties with high disaster resilience, however, we see that these outmigration patterns differ drastically. As the dotted lines in both plots show, individuals living in high resilience counties are generally less likely to move out following disasters. In both extended models, this finding holds for the range of observed income except in the poorest counties where disaster-related property damage has a statistically imperceptible effect on outmigration.

Our results here first provide systematic evidence suggesting that disaster resilience has an attenuating effect on income-based inequality in post-disaster migration. Further, this finding directly speaks to the dualistic nature of disaster resilience. Specifically, what is the net effect on outmigration of disaster resilience given that alleviating the dangers of climate impacts will make it easier for individuals to relocate but also reduce their incentives to do so? Our results indicate that the latter effect is stronger, as higher resilience is associated with lower post-disaster outmigration among richer areas rather than higher post-disaster outmigration among poorer areas. The economically capable, who have the means to relocate - which they do in low resilience areas - choose instead to stay. As we previously discussed, relocation and resilience building are substitute climate change adaptation measures, and given sufficient existing resilience, it appears that in situ incremental adaptations is generally more attractive. 


\subsection{Climate Factors Associated with Inmigration}

In addition to studying outmigration patterns, our understanding of relocation as a climate change adaptation measure also benefits from considering how climate factors impact where people move to. Not only is this relevant to assessing how effective the net effect of relocation is (Eyer et al. 2018), migration is generally important in itself because it drives social reorganization (Liu, Andris and Desmarais 2019; Feng, Oppenheimer and Schlenker 2012). Our county-to-county migration flow data allows us to look at these inmigration patterns. We focus on two primary findings, which correspond to the factors we looked at for outmigration.

First, we again find richer and poorer areas faring differently after exposure to natural disasters. This is most readily evident from the marginal effect plot on the right-hand side of Figure 4, which shows how the percent change in county-level inmigration given median observed values of property damage varies by county-level income.

As the figure shows, our model estimates poorer counties to experience decreased inmigration after natural disasters while richer counties are expected to see increased inmigration given disaster-related property damages. These results echo prior work that find natural disasters to have a pull on inmigration both in the U.S. (Eyer et al. 2018) and abroad (Naik, Stigter and Laczko 2007). This phenomenon occurs for a host of reasons, including increased demand for labor to rebuild the afflicted areas or because individuals from disaster-afflicted regions will congregate to economically-developed locales within the region. Together, these patterns imply that richer counties will end up with more resources to rebuild after a disaster while poorer counties will find it difficult to access proper resources to cope with damages (Masozera, Bailey and Kerchner 2007; McCaughey et al. 2018). Again, our results indicate that natural disasters may have a disproportionate impact on low-income households not only in terms of the accessibility of relocation as an adaptative measure, but also in how societal resources become distributed across areas.

Finally, we find that a county's level of resilience does not appear to be a serious consideration when individuals decide where they move to, which is apparent from the statistically insignificant or negative coefficient estimates on the two receiver resilience terms shown in Figure 3. This finding corroborates other studies that show individuals do not consider climate-related factors when deciding where they move to (Bell et al. 2021; Hino and Burke 2021), and implies that outmigration needs to be coupled with incentives for moving to resilient areas to be a viable climate adaptation measure. 


\section{Conclusion}

In this study we considered post-disaster relocation as a climate change adaptation measure by looking at how internal migration patterns in the U.S. varied by disaster-related property damage, household income, and local-level disaster resilience. We show that existing economic inequalities can lead to unfairness in access to measures of climate change adaptation. While relocation is arguably an increasingly necessary climate adaption measure (Kates, Travis and Wilbanks 2012), it may only be viable for certain segments of the population, leaving those lacking the necessary resources to relocated trapped in areas most vulnerable to the effects of climate change.

Additionally, income-based variations in post-disaster migration patterns could also exacerbate socioeconomic segregation, as we find evidence that disaster-afflicted areas differ considerably by wealth in their ability to attract inmigration after being exposed to natural disasters. This implies that comparatively speaking, richer counties will have greater access to resources for rebuilding from natural disasters. Our results here fit with and further contribute to a growing body of literature that emphasizes socioeconomic sorting as a major driver of vulnerability to climate change (Boustan et al. 2020; McCaughey et al. 2018; Feng, Oppenheimer and Schlenker 2012).

Finally, we find that income-based inequalities in post-disaster migration tend to be attenuated in areas with higher disaster resilience, with individuals living in these areas generally less likely to relocate following disasters regardless of the income level in their

county. This speaks to how disaster resilience incentivizes in situ adaptation rather than transformational adaptation approaches such as relocation (Binder, Baker and Barile 2015).

Our findings have several policy implications for climate change adaptation. While residential relocation is an individually autonomous adaptation measure, it is subject to unfairness that align with existing socioeconomic inequalities. Efforts to improve local resilience appear to alleviate these inequalities and reduce climate-related socioeconomic segregation. At the same time, it is important that these measures do not introduce perverse incentives that keep individuals in vulnerable areas, which can additionally be taxing on individual wellbeing (Koslov et al. 2021) and on climate governance resources in the longer term (Anderson et al. 2019).

Speaking to this, future research might explore how policy incentives can reduce climaterelated inequalities while promoting outmigration from vulnerable areas. One avenue worth exploring are policies that aim to reconcile the inconsistency between insurance payout for relocation and those for rebuilding, such as for example the recent push in California to enforce nondiscrimination for relocation in its insurance code (United Policyholders 2021). 
On this final point, it is critical to be cognizant that individuals generally do not consider the disaster resilience of where they move to, meaning that whether through incentives or greater awareness, policies should aim to encourage relocation specifically to climate resilient areas. 


\section{References}

Adams, Helen and W Neil Adger. 2013. Changing places: migration and adaptation to climate change. In $A$ Changing Environment for Human Security: Transformative Approaches to Research, Policy and Action, ed. Linda Sygna, Karen O'Brien and Johanna Wolf. Routledge-Earthscan.

Aldrich, Daniel P. 2012. Building resilience: Social capital in post-disaster recovery. University of Chicago Press.

Aldrich, Daniel P and Michelle A Meyer. 2015. "Social capital and community resilience." American behavioral scientist 59(2):254-269.

Anderson, Sarah E, Terry L Anderson, Alice C Hill, Matthew E Kahn, Howard Kunreuther, Gary D Libecap, Hari Mantripragada, Pierre Mérel, Andrew J Plantinga and V Kerry Smith. 2019. "The critical role of markets in climate change adaptation." Climate Change Economics 10(01):1950003.

Angelucci, Manuela. 2015. "Migration and financial constraints: Evidence from Mexico." Review of Economics and Statistics 97(1):224-228.

Bell, AR, DJ Wrathall, V Mueller, J Chen, M Oppenheimer, M Hauer, H Adams, S Kulp, PU Clark, E Fussell et al. 2021. "Migration towards Bangladesh coastlines projected to increase with sea-level rise through 2100." Environmental Research Letters 16(2):024045.

Benetsky, Megan J, Charlynn A Burd and Melanie A Rapino. 2015. "Young Adult Migration: 2007-2009 to 2010-2012." American Community Survey Reports .

Binder, Sherri Brokopp, Charlene K Baker and John P Barile. 2015. "Rebuild or relocate? Resilience and postdisaster decision-making after Hurricane Sandy." American journal of community psychology 56(1):180-196.

Black, Richard, Nigel W Arnell, W Neil Adger, David Thomas and Andrew Geddes. 2013. "Migration, immobility and displacement outcomes following extreme events." Environmental Science 83 Policy 27:S32S43.

Borden, Kevin A and Susan L Cutter. 2008. "Spatial patterns of natural hazards mortality in the United States." International journal of health geographics 7(1):1-13.

Boustan, Leah Platt, Matthew E Kahn, Paul W Rhode and Maria Lucia Yanguas. 2020. "The effect of natural disasters on economic activity in US counties: A century of data." Journal of Urban Economics 118:103257.

Butts, Carter T. 2020. sna: Tools for Social Network Analysis. R package version 2.6. URL: https://CRAN.R-project.org/package=sna

Buzkova, Petra. 2016. "Interaction testing: residuals-based permutations and parametric bootstrap in continuous, count, and binary data." Epidemiologic Methods 5(1):119-128.

CEMHS. 2020. "Spatial Hazard Events and Losses Database for the United States, Version 19.0 [Online Database]." Phoenix, AZ: Center for Emergency Management and Homeland Security, Arizona State University.

Chen, Justine, Ted Hsuan Yun Chen, Ilan Vertinsky, Lilia Yumagulova and Chansoo Park. 2013. "Publicprivate partnerships for the development of disaster resilient communities." Journal of contingencies and crisis management 21(3):130-143.

Clemens, Michael A. 2014. Does development reduce migration? In International handbook on migration and economic development. Edward Elgar Publishing. 
Cortés, Kristle Romero and Philip E Strahan. 2017. "Tracing out capital flows: How financially integrated banks respond to natural disasters." Journal of Financial Economics 125(1):182-199.

Cox, Robin S and Karen-Marie Elah Perry. 2011. "Like a fish out of water: Reconsidering disaster recovery and the role of place and social capital in community disaster resilience." American journal of community psychology 48(3):395-411.

Cutter, Susan L, Kevin D Ash and Christopher T Emrich. 2014. "The geographies of community disaster resilience." Global environmental change 29:65-77.

Cutter, Susan L and Sahar Derakhshan. 2020. "Temporal and spatial change in disaster resilience in US counties, 2010-2015." Environmental Hazards 19(1):10-29.

Dekker, David, David Krackhardt and Tom AB Snijders. 2007. "Sensitivity of MRQAP tests to collinearity and autocorrelation conditions." Psychometrika 72(4):563-581.

Doktycz, Charles and Mark Abkowitz. 2019. "Loss and damage estimation for extreme weather events: State of the practice." Sustainability 11(15):4243.

Elliott, James R. 2015. "Natural hazards and residential mobility: General patterns and racially unequal outcomes in the United States." Social Forces 93(4):1723-1747.

Eyer, Jonathan, Robert Dinterman, Noah Miller and Adam Rose. 2018. "The effect of disasters on migration destinations: evidence from Hurricane Katrina." Economics of disasters and climate change 2(1):91-106.

Federal Emergency Management Agency. 2021. "Community Resilience." https://hazards.fema.gov/nri/ community-resilience. (Last accessed: August 24, 2021).

Feliciano, Cynthia. 2005. "Educational selectivity in US immigration: How do immigrants compare to those left behind?" Demography 42(1):131-152.

Feng, Shuaizhang, Michael Oppenheimer and Wolfram Schlenker. 2012. "Climate change, crop yields, and internal migration in the United States.".

Freedman, David and David Lane. 1983. "A nonstochastic interpretation of reported significance levels." Journal of Business \&5 Economic Statistics 1(4):292-298.

Hauer, Mathew E, Jason M Evans and Deepak R Mishra. 2016. "Millions projected to be at risk from sea-level rise in the continental United States." Nature Climate Change 6(7):691-695.

Hino, Miyuki and Marshall Burke. 2021. "The effect of information about climate risk on property values." Proceedings of the National Academy of Sciences 118(17).

Hopkins, Daniel J. 2012. "Flooded communities: Explaining local reactions to the Post-Katrina migrants." Political Research Quarterly 65(2):443-459.

Howell, Junia and James R Elliott. 2019. "Damages done: The longitudinal impacts of natural hazards on wealth inequality in the United States." Social Problems 66(3):448-467.

Insurance Information Institute. 2021. "Settling insurance claims after a disaster." https://www.iii.org/ article/settling-insurance-claims-after-a-disaster. Last accessed: September 6, 2021.

Kates, Robert W, William R Travis and Thomas J Wilbanks. 2012. "Transformational adaptation when incremental adaptations to climate change are insufficient." Proceedings of the National Academy of Sciences 109(19):7156-7161. 
Kick, Edward L, James C Fraser, Gregory M Fulkerson, Laura A McKinney and Daniel H De Vries. 2011. "Repetitive flood victims and acceptance of FEMA mitigation offers: an analysis with community-system policy implications." Disasters 35(3):510-539.

Koslov, Liz, Alexis Merdjanoff, Elana Sulakshana and Eric Klinenberg. 2021. "When rebuilding no longer means recovery: the stress of staying put after Hurricane Sandy." Climatic change 165(3):1-21.

Kossin, James P. 2018. "A global slowdown of tropical-cyclone translation speed." Nature 558(7708):104.

Krackhardt, David. 1988. "Predicting with networks: Nonparametric multiple regression analysis of dyadic data." Social networks 10(4):359-381.

Leary, Neil A. 1999. "A framework for benefit-cost analysis of adaptation to climate change and climate variability." Mitigation and adaptation strategies for global change 4(3):307-318.

Liu, Xi, Clio Andris and Bruce A Desmarais. 2019. "Migration and political polarization in the US: An analysis of the county-level migration network." PloS one 14(11):e0225405.

Masozera, Michel, Melissa Bailey and Charles Kerchner. 2007. "Distribution of impacts of natural disasters across income groups: A case study of New Orleans." Ecological Economics 63(2-3):299-306.

McCaughey, Jamie W, Patrick Daly, Ibnu Mundir, Saiful Mahdi and Anthony Patt. 2018. "Socio-economic consequences of post-disaster reconstruction in hazard-exposed areas." Nature Sustainability 1(1):38-43.

McLeman, Robert A and Lori M Hunter. 2010. "Migration in the context of vulnerability and adaptation to climate change: insights from analogues." Wiley Interdisciplinary Reviews: Climate Change 1(3):450-461.

Mills, Mary Alice, Donald Edmondson and Crystal L Park. 2007. "Trauma and stress response among Hurricane Katrina evacuees." American journal of public health 97(Supplement_1):S116-S123.

Molloy, Raven, Christopher L Smith and Abigail Wozniak. 2011. "Internal migration in the United States." Journal of Economic perspectives 25(3):173-96.

Moore, R. 2017. "Seeking higher ground: How to break the cycle of repeated flooding with climate-smart flood insurance reforms." Natural Resources Defense Council Issue Brief.

Mossaad, Nadwa, Jeremy Ferwerda, Duncan Lawrence, Jeremy Weinstein and Jens Hainmueller. 2020. "In search of opportunity and community: Internal migration of refugees in the United States." Science advances $6(32)$ :eabb0295.

Naik, Asmita, Elca Stigter and Frank Laczko. 2007. "Migration, Development and Natural Disasters: Insights from the Indian Ocean Tsunami." International Organization for Migration.

Papathoma-Köhle, M, T Thaler and S Fuchs. 2021. "An institutional approach to vulnerability: evidence from natural hazard management in Europe." Environmental Research Letters 16(4):044056.

Piguet, Etienne, Antoine Pécoud and Paul De Guchteneire. 2011. "Migration and climate change: An overview." Refugee Survey Quarterly 30(3):1-23.

R Core Team. 2021. R: A Language and Environment for Statistical Computing. Vienna, Austria: R Foundation for Statistical Computing.

URL: https://www.R-project.org/

Schon, Justin and Jeffrey C Johnson. 2021. "How inter-state amity and animosity complement migration networks to drive refugee flows: A multi-layer network analysis, 1991-2016." Plos one 16(1):e0245712.

Shultz, James M and Sandro Galea. 2017. "Mitigating the mental and physical health consequences of Hurricane Harvey." Jama 318(15):1437-1438. 
Tierney, Kathleen. 2012. "Disaster governance: Social, political, and economic dimensions." Annual Review of Environment and Resources 37:341-363.

Trenberth, Kevin E, John T Fasullo and Theodore G Shepherd. 2015. "Attribution of climate extreme events." Nature Climate Change 5(8):725.

United Policyholders. 2021. "Buy or Rebuild?" https://uphelp.org/claim-guidance-publications/ buy-or-rebuild/. Last accessed: September 6, 2021.

Warner, Koko and Tamer Afifi. 2014. "Where the rain falls: Evidence from 8 countries on how vulnerable households use migration to manage the risk of rainfall variability and food insecurity." Climate and Development 6(1):1-17.

Wing, Oliver EJ, Paul D Bates, Andrew M Smith, Christopher C Sampson, Kris A Johnson, Joseph Fargione and Philip Morefield. 2018. "Estimates of present and future flood risk in the conterminous United States." Environmental Research Letters 13(3):034023.

Wolf, Johanna, W Neil Adger, Irene Lorenzoni, Vanessa Abrahamson and Rosalind Raine. 2010. "Social capital, individual responses to heat waves and climate change adaptation: An empirical study of two UK cities." Global Environmental Change 20(1):44-52.

Zuzak, Casey, David Kealey, Emily Goodenough and Carly Stanton. 2020. "National Risk Index Technical Documentation." Federal Emergency Management Agency, Washington, DC. 


\section{A Confounding Variables}

We identify a number of social, economic, and political factors that can confound our inference. First, we include a set of geographic variables that may affect migration flows. Specifically, we include whether migration flows connect counties within the same state and how far the distance is to account for migration decisions based on cultural familiarity and geographical proximity.

Second, we consider county-specific sociodemographic variables such as population, median age, the percentage of native born residents, and percentage of bachelor degree holders. The size of the population in a county may drive a higher value of property damages as well as more migration flows. Also, young people tend to migrate more for work or study (Benetsky, Burd and Rapino 2015), and people with higher education tend to have broader migration options (Feliciano 2005). The percentage of native born residents is also included to control for the effect of the attachment to place, as individuals born in the state of current residence may feel more attached to where they live. This variable help us separate out the effect of attachment to place from the community capital measure, which capture the whole community engagement approach to emergencies rather than an emotional attachment to the community.

Third, we control for a set of economic conditions, including the percentage of nonhispanic white population, the percentage of people unemployed, and the percentage of people employed in the manufacturing industry, based on the North American Industry Classification System (NAICS). Predominantly White neighborhoods may have more options in the face of natural hazards (Howell and Elliott 2019; Elliott 2015). Also, although people may move to a region with more employment opportunities, they may be specifically drawn to areas where job openings specific to their skills are abundant (Mossaad et al. 2020). We thus include a share of manufacturing sector employees in a county using employment data by industry retrieved from NAICS. The data are further aggregated to either manufacturing or service sector, following the classification by the U.S. Bureau of Labor statistics.

Fourth, migration flows may be driven by political ideology (Liu, Andris and Desmarais 2019). To account for this, we include the percentage of republican support based on countylevel presidential election results, where values for non-elections years are interpolated based on county-level presidential election results on 2008, 2012, 2016, and 2020.

Finally, we also control for disaster-induced bodily harm because it may contribute to the decision to migrate by directly threatening physical safety (Boustan et al. 2020). The original variables from SHELDUS are recorded with the raw count of people injured or killed by weather events, which we transformed to log form. 


\section{B Descriptive Statistics}

\section{B.1 Community Capital and Institutional Capacity}

In Figure B.1, we show the joint and marginal distributions of the community capital and institutional capacity resilience measures across years. The data is obtained from the Baseline Resilience Indicators for Communities (Cutter, Ash and Emrich 2014; Cutter and Derakhshan 2020). The main observation from these figures is that the two measures do not relate to each other strongly, which indicates that our findings that the two resilience measures are both associated with lower income-based inequality in post-disaster migration are independently meaningful. Second, both measures are relatively consistent across years, which reduces concerns about having only two time points for the ten-year period.

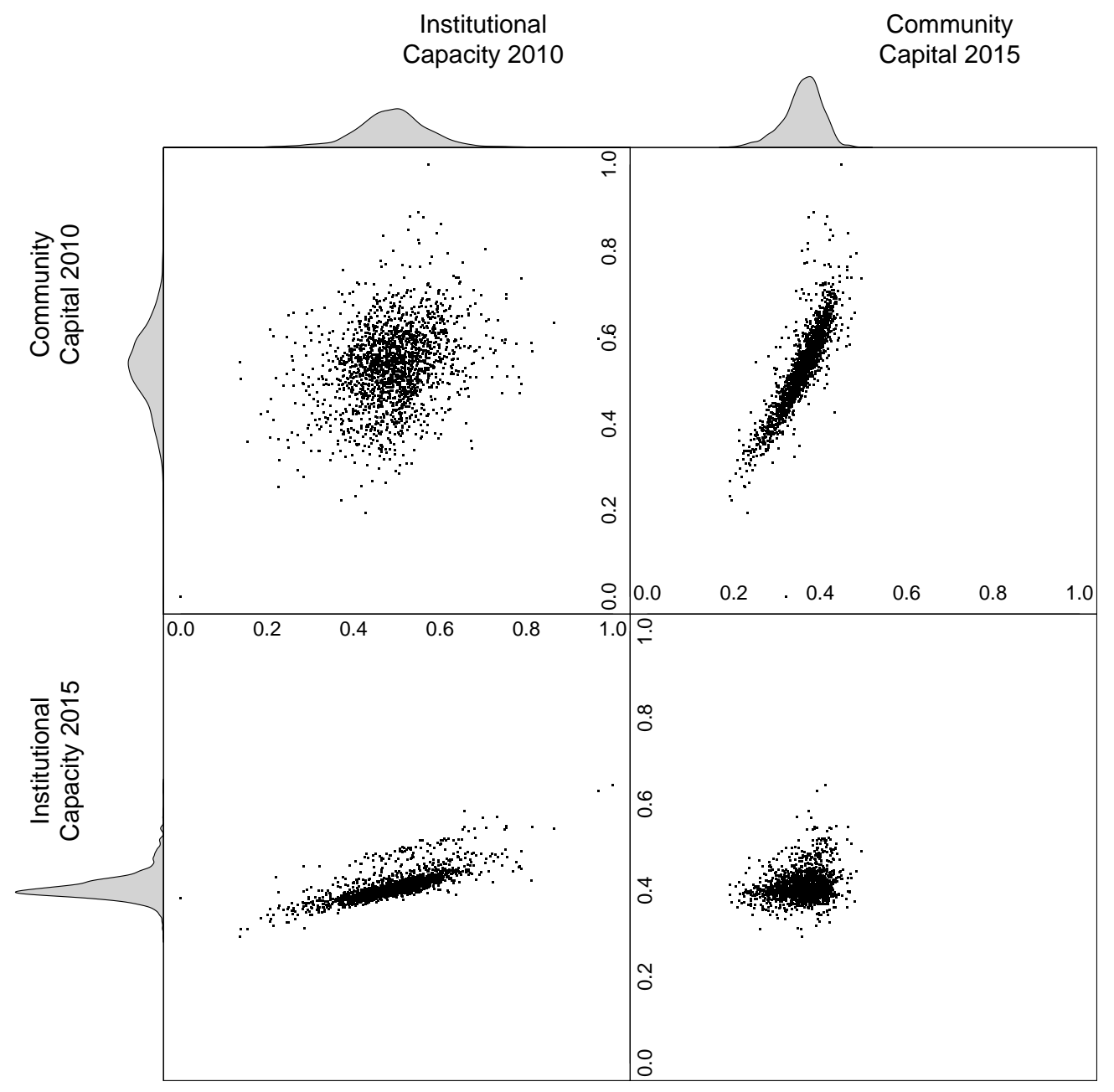

Figure B.1: Joint and marginal distributions of resilience measures. Each point represents a U.S. county that is not in Hawaii or Alaska, and has a population size larger than 20,000 according to the 2010 census. 


\section{B.2 Property Damage, Household Income, and Disaster Resilience}

In Figure B.2, we show the joint distribution of property damage, median household income, and, separately, the two disaster resilience measures by year. The grey lines mark, by year, the first and $99^{\text {th }}$ percentiles of observed household income, which is the range shown in the marginal effect plots in the main text. Similarly, the orange lines mark the first and third quartiles of disaster resilience, which were the values used for the low and high resilience curves in the marginal effect plots.

The distribution of figures here indicate that the values used for the marginal effect plots are reasonable values with good coverage in the observed data.
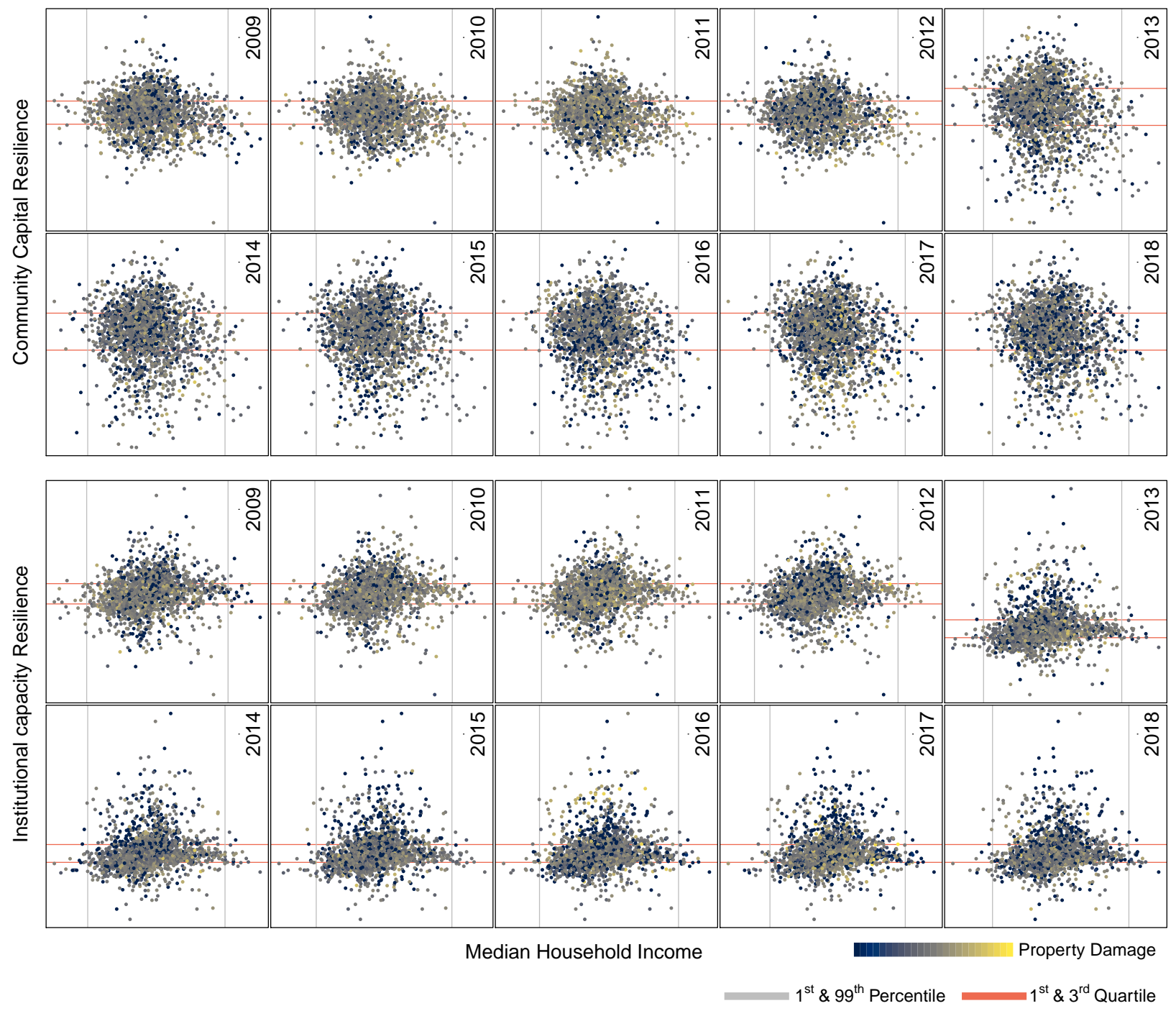

Figure B.2: Joint distribution of property damage, household income, and resilience. Each point represents a U.S. county that is not in Hawaii or Alaska, and has a population size larger than 20,000 according to the 2010 census. Points are distributed on the x-axis by median household income, on the $\mathrm{y}$-axis by a resilience measure, and coloured by property damage. 


\section{Quadratic Assignment Procedure}

The multiple regression quadratic assignment procedure (MRQAP) is a permutation method for constructing null distributions for hypothesis testing in models of network data (Krackhardt 1988). Current approaches to MRQAP permute residuals instead of outcome or predictor variables, which is important because hypothesis tests based on raw data permutation are sensitive to data issues or testing parameters (Dekker, Krackhardt and Snijders 2007).

To test individual coefficients, we use the standard implementation of the MRQAP test from the sna package (Butts 2020) in R (R Core Team 2021), which relies on the doublesemi partialling (DSP) residual permutation method described in Dekker, Krackhardt and Snijders (2007). Simulation studies show that this has desirable properties in the multiple regression context when conducting hypothesis tests on single coefficients $\beta_{k}$ where the null hypothesis is $\beta_{k}=0$, particularly when working with interactive effects (Buzkova 2016). We use the DSP method to conduct independent tests for each of the ten coefficients in our base model and each of the seven coefficients tested in the two respective extended models. Other predictors are treated as nuisance terms, so we do not test their coefficients.

Beyond examining the coefficients on our predictors of interest, we rely on a series of marginal effect plots to interpret the higher ordered interaction effects from our model results. To show the range of observed data under which these marginal effects are significantly different from zero, we compare the marginal effect curves against a null distribution also constructed using the MRQAP. For these tests, the DSP method does not work, because it tests each model term independently after partialling out the effect of all other model terms, preventing us from constructing a null distribution that incorporates covariation between the interaction terms and their base terms. Instead, we used another residual-based permutation method, the Freedman-Lane semi-partialling method (Freedman and Lane 1983). This method more flexibly allows for an arbitrary number of model terms to be jointly tested, making it possible to construct null distributions that incorporate covariation between the tested terms, which in our case are the interaction terms in question and their base terms. Simulation studies show that the FLSP method has the same desirable properties as the DSP method (Dekker, Krackhardt and Snijders 2007).

\section{Model Results}

Table D.2, Table D.3, and Table D.4 contain all coefficient estimates for the models in our study. As noted, we only conducted hypothesis tests for predictors of interest, which are organized above the horizontal bar in each table. 


\begin{tabular}{|c|c|c|c|c|c|c|c|c|c|c|}
\hline & 2009 & 2010 & 2011 & 2012 & 2013 & 2014 & 2015 & 2016 & 2017 & 2018 \\
\hline Income $(\mathrm{s})$ & $-0.098^{*}$ & $-0.152^{*}$ & $-0.079^{*}$ & -0.061 & $-0.047^{*}$ & $-0.065^{*}$ & -0.045 & $-0.069^{*}$ & $-0.054^{*}$ & $-0.051^{*}$ \\
\hline Income $(r)$ & $-0.095^{*}$ & $-0.150^{*}$ & -0.080 & $-0.071^{*}$ & $-0.074^{*}$ & $-0.068^{*}$ & $-0.070^{*}$ & $-0.098^{*}$ & $-0.079^{*}$ & $-0.052^{*}$ \\
\hline Community Capital (s) & $-0.338^{*}$ & $-0.335^{*}$ & $-0.375^{*}$ & $-0.404^{*}$ & $-0.606^{*}$ & $-0.522^{*}$ & $-0.620^{*}$ & $-0.768^{*}$ & $-0.665^{*}$ & $-0.625^{*}$ \\
\hline Community Capital (r) & $-0.381^{*}$ & $-0.386^{*}$ & $-0.411^{*}$ & $-0.448^{*}$ & $-0.696^{*}$ & $-0.586^{*}$ & $-0.727^{*}$ & $-0.891^{*}$ & $-0.746^{*}$ & $-0.700^{*}$ \\
\hline Institutional Capacity (s) & $-0.125^{*}$ & $-0.123^{*}$ & $-0.129 *$ & $-0.118^{*}$ & -0.118 & -0.031 & -0.093 & -0.132 & -0.116 & -0.098 \\
\hline Institutional Capacity (r) & $-0.115^{*}$ & $-0.113^{*}$ & $-0.119^{*}$ & $-0.099 *$ & -0.071 & -0.007 & -0.028 & -0.085 & -0.076 & -0.080 \\
\hline Property Damage (r) & $-0.060^{*}$ & $-0.116^{*}$ & -0.055 & -0.051 & $-0.066^{*}$ & $-0.072^{*}$ & $-0.049^{*}$ & $-0.068^{*}$ & $-0.068^{*}$ & $-0.041^{*}$ \\
\hline Property Damage (s) & $-0.085^{*}$ & $-0.141^{*}$ & $-0.068^{*}$ & $-0.062^{*}$ & $-0.054^{*}$ & $-0.084^{*}$ & $-0.048^{*}$ & $-0.070^{*}$ & $-0.067^{*}$ & $-0.048^{*}$ \\
\hline Income $\times$ Property $(\mathrm{s})$ & $0.008^{*}$ & $0.013^{*}$ & 0.006 & $0.006^{*}$ & $0.005^{*}$ & $0.008^{*}$ & $0.004^{*}$ & $0.006^{*}$ & $0.006^{*}$ & $0.004^{*}$ \\
\hline$\times$ Prop & $0.005^{*}$ & $0.011^{*}$ & 0.005 & $0.005^{*}$ & $0.006^{*}$ & $0.007^{*}$ & $0.005^{*}$ & $0.006^{*}$ & $0.006^{*}$ & $0.004^{*}$ \\
\hline Same State & 0.772 & 0.785 & 0.8 & 0.832 & 0.617 & 0.530 & 0.629 & 0.731 & 0.639 & 0.629 \\
\hline Distance & -0.135 & -0.135 & -0.146 & -0.145 & -0.109 & -0.095 & -0.111 & -0.129 & -0.115 & -0.111 \\
\hline Population (h) & -0.093 & -0.098 & -0.106 & -0.110 & -0.073 & -0.059 & -0.076 & -0.095 & -0.078 & -0.078 \\
\hline Popul & 0.121 & 0.1 & 0.137 & 0.137 & & & & 0.109 & & 0.088 \\
\hline Populatio & 0.121 & 0.123 & 0.137 & 0.136 & 0.085 & 0.063 & 0.084 & 0.106 & 0.088 & 0.086 \\
\hline Age $(\mathrm{h})$ & -0.003 & -0.003 & -0.003 & -0.003 & -0.002 & -0.002 & -0.003 & -0.003 & -0.002 & -0.002 \\
\hline & 0.003 & 0.0 & 0.0 & 0.0 & 0.00 & 0.003 & 0.003 & & & \\
\hline Age (r) & 0.004 & 0.004 & 0.006 & 0.006 & 0.004 & 0.003 & 0.004 & 0.005 & 0.004 & 0.003 \\
\hline Bachelor (h) & -0.004 & -0.004 & -0.004 & -0.004 & -0.002 & -0.001 & -0.002 & -0.003 & -0.002 & -0.002 \\
\hline $\mathrm{Bac}$ & 0.0 & & & & & 0.001 & 0.002 & 0.003 & & 0.002 \\
\hline $\mathrm{Bac}$ & 0.005 & 0.006 & 0.006 & 0.006 & 0.003 & 0.002 & 0.003 & 0.005 & 0.002 & 0.003 \\
\hline Unemploy & 0.009 & 0.007 & 0.006 & 0.005 & 0.003 & 0.003 & 0.003 & 0.006 & 0.006 & 0.006 \\
\hline Unemploy & -0.016 & -0.012 & -0.010 & -0.0 & -0.007 & -0.006 & -0.008 & -0.011 & -0.0 & -0.008 \\
\hline Unemployment (r) & -0.016 & -0.013 & -0.010 & -0.010 & -0.007 & -0.007 & -0.009 & -0.011 & -0.013 & -0.010 \\
\hline Income $(\mathrm{h})$ & -0.063 & -0.077 & -0.070 & -0.073 & -0.035 & -0.037 & -0.021 & -0.015 & -0.012 & -0.020 \\
\hline hite (h) & -0.094 & -0.090 & -0.096 & -0.098 & -0.067 & -0.056 & -0.069 & -0.080 & -0.072 & -0.061 \\
\hline White (s) & -0.212 & -0.198 & -0.233 & -0.241 & -0.144 & -0.121 & -0.129 & -0.151 & -0.130 & -0.117 \\
\hline White (r) & -0.228 & -0.217 & -0.248 & -0.252 & -0.152 & -0.125 & -0.130 & -0.156 & -0.133 & -0.128 \\
\hline Native Residents (s) & 0.347 & 0.341 & 0.411 & 0.432 & 0.218 & 0.202 & 0.170 & 0.177 & 0.164 & 0.037 \\
\hline Native Residents (r) & 0.418 & 0.411 & 0.508 & 0.544 & 0.353 & 0.307 & 0.296 & 0.341 & 0.304 & 0.224 \\
\hline Manufacturing (h) & -0.133 & -0.129 & -0.152 & -0.168 & -0.100 & -0.073 & -0.112 & -0.142 & -0.103 & -0.119 \\
\hline GOP $(\mathrm{h})$ & -0.124 & -0.127 & -0.130 & -0.134 & -0.094 & -0.082 & -0.113 & -0.159 & -0.122 & -0.119 \\
\hline GOP (s) & -0.142 & -0.142 & -0.144 & -0.135 & -0.106 & -0.104 & -0.153 & -0.183 & -0.160 & -0.134 \\
\hline GOP (r) & -0.112 & -0.118 & -0.106 & -0.086 & -0.078 & -0.083 & -0.119 & -0.128 & -0.125 & -0.096 \\
\hline Bodily harm (r) & 0.010 & 0.024 & 0.013 & 0.029 & 0.022 & 0.024 & 0.035 & 0.038 & 0.026 & 0.038 \\
\hline Bodily Harm (s) & 0.013 & 0.023 & 0.013 & 0.032 & 0.020 & 0.024 & 0.030 & 0.036 & 0.026 & 0.040 \\
\hline Intercept & 1.275 & 2.350 & 0.527 & 0.214 & 0.936 & 1.296 & 0.923 & 1.295 & 1.134 & 0.784 \\
\hline
\end{tabular}

$\mathrm{s}=$ sender; $\mathrm{r}=$ receiver; $\mathrm{h}=$ homophily. Hypothesis tests only conducted for terms above the middle bar; $* \mathrm{p}<0.05$.

Table D.2: Base Model for All Years. 


\begin{tabular}{|c|c|c|c|c|c|c|c|c|c|c|}
\hline & 2009 & 2010 & 2011 & 2012 & 2013 & 2014 & 2015 & 2016 & 2017 & 2018 \\
\hline Income $(\mathrm{s})$ & 0.059 & $-0.484^{*}$ & -0.089 & -0.137 & -0.053 & $-0.273^{*}$ & $-0.353^{*}$ & $0.267^{*}$ & 0.175 & 0.263 \\
\hline Community Capital (s) & 2.926 & $-6.833^{*}$ & -0.193 & -1.892 & -0.123 & $-6.238^{*}$ & $-9.165^{*}$ & $10.038^{*}$ & $6.328^{*}$ & $9.136^{*}$ \\
\hline Property Damage (s) & $-0.292^{*}$ & $-0.713^{*}$ & $-0.388^{*}$ & $-0.413^{*}$ & $-0.643^{*}$ & $-0.697^{*}$ & $-0.950^{*}$ & $-0.612^{*}$ & $-0.538^{*}$ & $-0.334^{*}$ \\
\hline Income $\times$ Community $(\mathrm{s})$ & -0.283 & $0.636^{*}$ & 0.004 & 0.158 & -0.010 & $0.572^{*}$ & $0.833^{*}$ & $-0.970^{*}$ & -0.601 & $-0.868^{*}$ \\
\hline Property $\times$ Income (s) & $0.028^{*}$ & $0.068^{*}$ & $0.037^{*}$ & $0.039^{*}$ & $0.061^{*}$ & $0.066^{*}$ & $0.090 *$ & $0.058^{*}$ & $0.051^{*}$ & $0.032^{*}$ \\
\hline Property $\times$ Community (s) & 0.426 & $1.120^{*}$ & $0.624^{*}$ & $0.711^{*}$ & $1.657^{*}$ & $1.746^{*}$ & $2.540^{*}$ & $1.507^{*}$ & $1.383^{*}$ & $0.823 *$ \\
\hline Prop $\times$ Inc $\times$ Community (s) & $-0.042^{*}$ & $-0.107^{*}$ & $-0.060^{*}$ & $-0.068^{*}$ & $-0.158^{*}$ & $-0.167^{*}$ & $-0.241^{*}$ & $-0.144^{*}$ & $-0.133^{*}$ & $-0.079 *$ \\
\hline Same State & 0.772 & 0.787 & 0.817 & 0.834 & 0.618 & 0.530 & 0.630 & 0.733 & 0.639 & 0.630 \\
\hline Distance & -0.135 & -0.134 & -0.144 & -0.144 & -0.109 & -0.095 & -0.110 & -0.129 & -0.115 & -0.110 \\
\hline Population (h) & -0.094 & -0.099 & -0.106 & -0.111 & -0.074 & -0.060 & -0.078 & -0.096 & -0.080 & -0.079 \\
\hline Population (s) & 0.122 & 0.121 & 0.138 & 0.136 & 0.086 & 0.062 & 0.083 & 0.107 & 0.089 & 0.087 \\
\hline Population (r) & 0.121 & 0.123 & 0.137 & 0.137 & 0.085 & 0.064 & 0.084 & 0.107 & 0.089 & 0.087 \\
\hline Age $(\mathrm{h})$ & -0.003 & -0.003 & -0.003 & -0.003 & -0.002 & -0.001 & -0.002 & -0.003 & -0.002 & -0.002 \\
\hline Age (s) & 0.003 & 0.003 & 0.004 & 0.004 & 0.003 & 0.002 & 0.003 & 0.003 & 0.002 & 0.002 \\
\hline Age $(r)$ & 0.004 & 0.004 & 0.006 & 0.006 & 0.004 & 0.003 & 0.004 & 0.005 & 0.004 & 0.003 \\
\hline Bachelor (h) & -0.004 & -0.004 & -0.004 & -0.004 & -0.002 & -0.001 & -0.002 & -0.003 & -0.002 & -0.002 \\
\hline Bachelor (s) & 0.004 & 0.004 & 0.005 & 0.005 & 0.002 & 0.001 & 0.002 & 0.002 & 0.001 & 0.001 \\
\hline Bachelor (r) & 0.005 & 0.006 & 0.006 & 0.006 & 0.003 & 0.002 & 0.003 & 0.005 & 0.002 & 0.003 \\
\hline Unemployment (h) & 0.010 & 0.007 & 0.006 & 0.005 & 0.003 & 0.003 & 0.004 & 0.007 & 0.007 & 0.007 \\
\hline Unemployment (s) & -0.018 & -0.012 & -0.011 & -0.011 & -0.008 & -0.007 & -0.009 & -0.013 & -0.012 & -0.009 \\
\hline Unemployment $(\mathrm{r})$ & -0.016 & -0.012 & -0.010 & -0.010 & -0.007 & -0.007 & -0.009 & -0.012 & -0.013 & -0.010 \\
\hline Income $(\mathrm{h})$ & -0.066 & -0.083 & -0.078 & -0.079 & -0.041 & -0.042 & -0.031 & -0.024 & -0.019 & -0.029 \\
\hline Income $(r)$ & -0.094 & -0.152 & -0.080 & -0.072 & -0.074 & -0.069 & -0.071 & -0.098 & -0.078 & -0.058 \\
\hline White (h) & -0.093 & -0.091 & -0.096 & -0.098 & -0.065 & -0.056 & -0.065 & -0.076 & -0.069 & -0.059 \\
\hline White (s) & -0.199 & -0.180 & -0.215 & -0.226 & -0.122 & -0.105 & -0.109 & -0.123 & -0.106 & -0.099 \\
\hline White $(\mathrm{r})$ & -0.229 & -0.217 & -0.248 & -0.252 & -0.153 & -0.126 & -0.131 & -0.156 & -0.133 & -0.126 \\
\hline Native Residents (s) & 0.354 & 0.323 & 0.376 & 0.389 & 0.158 & 0.175 & 0.142 & 0.151 & 0.169 & 0.059 \\
\hline Native Residents ( $\mathrm{r}$ ) & 0.412 & 0.394 & 0.488 & 0.527 & 0.337 & 0.295 & 0.274 & 0.319 & 0.290 & 0.183 \\
\hline Manufacturing (h) & -0.128 & -0.131 & -0.154 & -0.169 & -0.097 & -0.070 & -0.110 & -0.136 & -0.091 & -0.114 \\
\hline $\operatorname{GOP}(\mathrm{h})$ & -0.124 & -0.130 & -0.135 & -0.138 & -0.099 & -0.088 & -0.121 & -0.167 & -0.130 & -0.128 \\
\hline GOP $(\mathrm{s})$ & -0.144 & -0.141 & -0.138 & -0.129 & -0.109 & -0.104 & -0.157 & -0.193 & -0.162 & -0.133 \\
\hline GOP $(r)$ & -0.112 & -0.118 & -0.105 & -0.086 & -0.078 & -0.084 & -0.119 & -0.128 & -0.125 & -0.097 \\
\hline Community Capital (r) & -0.380 & -0.385 & -0.410 & -0.447 & -0.693 & -0.585 & -0.724 & -0.887 & -0.746 & -0.699 \\
\hline Institutional Capacity (s) & -0.105 & -0.099 & -0.109 & -0.111 & -0.049 & 0.008 & -0.078 & -0.036 & -0.107 & -0.056 \\
\hline Institutional Capacity (r) & -0.114 & -0.112 & -0.118 & -0.098 & -0.074 & -0.010 & -0.031 & -0.089 & -0.079 & -0.080 \\
\hline Bodily harm (r) & 0.010 & 0.024 & 0.013 & 0.029 & 0.022 & 0.024 & 0.035 & 0.038 & 0.026 & 0.038 \\
\hline Bodily Harm (s) & 0.011 & 0.021 & 0.013 & 0.030 & 0.020 & 0.021 & 0.028 & 0.034 & 0.023 & 0.035 \\
\hline Property Damage (r) & -0.060 & -0.117 & -0.056 & -0.052 & -0.067 & -0.073 & -0.050 & -0.068 & -0.068 & -0.040 \\
\hline Property:Income (r) & 0.005 & 0.011 & 0.005 & 0.005 & 0.006 & 0.007 & 0.005 & 0.006 & 0.006 & 0.004 \\
\hline Intercept & -0.547 & 5.725 & 0.494 & 0.933 & 0.840 & 3.384 & 4.102 & -2.480 & -1.504 & -2.705 \\
\hline
\end{tabular}

$\mathrm{s}=$ sender; $\mathrm{r}=$ receiver; $\mathrm{h}=$ homophily. Hypothesis tests only conducted for terms above the middle bar; ${ }^{*} \mathrm{p}<0.05$.

Table D.3: Extended Model with Community Capital Interaction Effect for All Years. 


\begin{tabular}{|c|c|c|c|c|c|c|c|c|c|c|}
\hline & 2009 & 2010 & 2011 & 2012 & 2013 & 2014 & 2015 & 2016 & 2017 & 2018 \\
\hline Income $(\mathrm{s})$ & -0.171 & $-0.539^{*}$ & -0.089 & $-0.329^{*}$ & -0.398 & $-0.447^{*}$ & -0.431 & -0.229 & -0.155 & 0.002 \\
\hline Institutional Capacity (s) & -1.512 & $-7.967^{*}$ & 0.269 & $-5.526^{*}$ & -8.911 & -9.156 & -9.365 & -3.811 & -2.373 & 1.891 \\
\hline Property Damage (s) & $-0.305^{*}$ & $-0.630^{*}$ & -0.230 & $-0.517^{*}$ & $-0.696^{*}$ & $-0.579^{*}$ & $-0.743^{*}$ & $-0.614^{*}$ & $-0.575^{*}$ & -0.294 \\
\hline Income $\times$ Institutional $(\mathrm{s})$ & 0.135 & $0.750^{*}$ & -0.020 & 0.513 & 0.840 & $0.884^{*}$ & 0.893 & 0.371 & 0.241 & -0.155 \\
\hline Property $\times$ Income $(\mathrm{s})$ & $0.029^{*}$ & $0.059^{*}$ & 0.022 & $0.048^{*}$ & $0.066^{*}$ & $0.056^{*}$ & $0.071^{*}$ & $0.058^{*}$ & $0.055^{*}$ & 0.029 \\
\hline Property $\times$ Institutional (s) & 0.449 & $0.980^{*}$ & 0.305 & $0.911^{*}$ & $1.562^{*}$ & $1.171^{*}$ & $1.663^{*}$ & $1.320^{*}$ & $1.242^{*}$ & 0.593 \\
\hline Prop $\times$ Inc $\times$ Institutional (s) & -0.042 & $-0.093^{*}$ & -0.030 & $-0.086^{*}$ & $-0.148^{*}$ & $-0.113^{*}$ & $-0.159^{*}$ & -0.126 & $-0.119^{*}$ & -0.059 \\
\hline Same State & 0.772 & 0.785 & 0.815 & 0.832 & 0.617 & 0.529 & 0.629 & 0.731 & 0.638 & 0.629 \\
\hline Distance & -0.135 & -0.135 & -0.146 & -0.145 & -0.109 & -0.096 & -0.111 & -0.130 & -0.116 & -0.111 \\
\hline Population (h) & -0.093 & -0.098 & -0.106 & -0.111 & -0.073 & -0.060 & -0.077 & -0.095 & -0.079 & -0.078 \\
\hline Population (s) & 0.121 & 0.120 & 0.137 & 0.136 & 0.085 & 0.062 & 0.084 & 0.108 & 0.090 & 0.088 \\
\hline Population (r) & 0.121 & 0.123 & 0.137 & 0.137 & 0.085 & 0.064 & 0.084 & 0.106 & 0.089 & 0.086 \\
\hline Age (h) & -0.003 & -0.003 & -0.003 & -0.003 & -0.002 & -0.002 & -0.003 & -0.003 & -0.002 & -0.002 \\
\hline Age (s) & 0.003 & 0.003 & 0.005 & 0.005 & 0.003 & 0.003 & 0.003 & 0.003 & 0.003 & 0.002 \\
\hline Age (r) & 0.004 & 0.004 & 0.006 & 0.006 & 0.004 & 0.003 & 0.004 & 0.005 & 0.004 & 0.003 \\
\hline Bachelor (h) & -0.004 & -0.004 & -0.004 & -0.004 & -0.002 & -0.001 & -0.002 & -0.003 & -0.002 & -0.002 \\
\hline Bachelor (s) & 0.004 & 0.005 & 0.005 & 0.005 & 0.002 & 0.001 & 0.002 & 0.003 & 0.001 & 0.002 \\
\hline Bachelor (r) & 0.005 & 0.006 & 0.006 & 0.006 & 0.003 & 0.002 & 0.003 & 0.005 & 0.002 & 0.002 \\
\hline Unemployr & 0.009 & 0.006 & 0.005 & 0.005 & 0.003 & 0.003 & 0.003 & 0.006 & 0.006 & 0.006 \\
\hline Unemployment (s) & -0.016 & -0.012 & -0.010 & -0.010 & -0.007 & -0.006 & -0.008 & -0.010 & -0.011 & -0.008 \\
\hline Unemployment (r) & -0.016 & -0.013 & -0.010 & -0.010 & -0.007 & -0.007 & -0.009 & -0.012 & -0.013 & -0.010 \\
\hline Income $(\mathrm{h})$ & -0.061 & -0.075 & -0.067 & -0.070 & -0.033 & -0.038 & -0.021 & -0.013 & -0.009 & -0.017 \\
\hline Income $(r)$ & -0.095 & -0.151 & -0.080 & -0.070 & -0.074 & -0.068 & -0.070 & -0.098 & -0.0 & -0.050 \\
\hline hite (h) & -0.094 & -0.091 & -0.096 & -0.099 & -0.067 & -0.057 & -0.068 & -0.079 & -0.071 & -0.061 \\
\hline White (s) & -0.209 & -0.194 & -0.234 & -0.238 & -0.142 & -0.123 & -0.125 & -0.147 & -0.129 & -0.116 \\
\hline White $(\mathrm{r})$ & -0.228 & -0.217 & -0.248 & -0.252 & -0.152 & -0.125 & -0.131 & -0.156 & -0.133 & -0.128 \\
\hline Native Resider & 0.318 & 0.303 & 0.359 & 0.370 & 0.200 & 0.202 & 0.163 & 0.151 & 0.164 & 0.029 \\
\hline Native Residents (r) & 0.421 & 0.412 & 0.509 & 0.545 & 0.356 & 0.307 & 0.296 & 0.344 & 0.309 & 0.233 \\
\hline Manufacturing (h) & -0.129 & -0.129 & -0.149 & -0.167 & -0.097 & -0.072 & -0.112 & -0.138 & -0.097 & -0.115 \\
\hline $\operatorname{GOP}(\mathrm{h})$ & -0.124 & -0.126 & -0.132 & -0.135 & -0.095 & -0.082 & -0.114 & -0.158 & -0.121 & -0.119 \\
\hline GOP (s) & -0.144 & -0.144 & -0.144 & -0.139 & -0.109 & -0.102 & -0.155 & -0.184 & -0.163 & -0.132 \\
\hline GOP $(r)$ & -0.112 & -0.118 & -0.106 & -0.086 & -0.078 & -0.084 & -0.119 & -0.128 & -0.125 & -0.097 \\
\hline Community Capital (s) & -0.335 & -0.337 & -0.372 & -0.412 & -0.604 & -0.517 & -0.630 & -0.769 & -0.663 & -0.619 \\
\hline Community Capital (r) & -0.380 & -0.386 & -0.411 & -0.447 & -0.696 & -0.587 & -0.728 & -0.891 & -0.747 & -0.700 \\
\hline Institutional Capacity (r) & -0.114 & -0.113 & -0.119 & -0.099 & -0.071 & -0.007 & -0.028 & -0.084 & -0.074 & -0.081 \\
\hline Bodily harm (r) & 0.010 & 0.024 & 0.013 & 0.029 & 0.022 & 0.024 & 0.035 & 0.038 & 0.026 & 0.038 \\
\hline Bodily Harm (s) & 0.013 & 0.022 & 0.013 & 0.031 & 0.020 & 0.023 & 0.029 & 0.036 & 0.025 & 0.040 \\
\hline Property Damage (r) & -0.061 & -0.116 & -0.055 & -0.051 & -0.067 & -0.072 & -0.049 & -0.068 & -0.069 & -0.042 \\
\hline Property:Income (r) & 0.005 & 0.011 & 0.005 & 0.005 & 0.006 & 0.007 & 0.005 & 0.006 & 0.006 & 0.004 \\
\hline Intercept & 2.027 & 6.405 & 0.543 & 3.052 & 4.616 & 5.240 & 4.935 & 2.889 & 2.086 & 0.062 \\
\hline
\end{tabular}

$\mathrm{s}=$ sender $\mathrm{r}=$ receiver; $\mathrm{h}=$ homophily. Hypothesis tests only conducted for terms above the middle bar; ${ }^{*} \mathrm{p}<0.05$.

Table D.4: Extended Model with Institutional Capacity Interaction Effect for All Years. 